\title{
Recurrent DNA copy number alterations in intestinal-type sinonasal adenocarcinoma*
}

\author{
Jhudit Pérez-Escuredo', Alejandro López-Hernández', María Costales', \\ Fernando López', Sira Potes Ares' ${ }^{1}$ Blanca Vivanco², José Luis Llorente', \\ Mario A. Hermsen'
}

Rhinology 54: 278-286, 2016

DOl:10.4193/Rhino15.382

*Received for publication:

December 22, 2015

Accepted: January 21, 2016

\begin{abstract}
Background: Intestinal-type sinonasal adenocarcinoma (ITAC) is a rare tumour related to occupational wood dust exposure. Few studies have described recurrent genetic changes on a genome-wide scale. The aim of this study was to obtain a high resolution map of recurrent genetic alterations in ITAC.
\end{abstract}

Material and methods: Copy number alterations were evaluated by microarray CGH and MLPA in 37 primary tumours. The results were correlated with pathological characteristics and clinical outcome.

Results: Microarray CGH identified the following recurrent aberrations, in descending order: gains at $5 p 15$ ( 22 cases, $60 \%), 8 q 24$ (21 cases, 57\%), 20q13 (20 cases, 54\%), 20q11, and 8q21 (19 cases, 51\%), 20p13, and 7p11 (16 cases, 43\%), and losses at 5q11-qter, 8p12-pter, and 18q12-23 (15 cases, 40\%), and 17p13, and 19p13 (13 cases, 35\%). MLPA analysis confirmed this global pattern of gains and losses. Chromosomal loss at 4q32-ter and gains at 1q22, 6p22 and 3q29, as well as deletion of TIMP2 and CRK correlated with unfavourable clinical outcome.

Conclusion: ITACs have a unique pattern of chromosomal abnormalities. The four different histological subtypes of ITAC appeared genetically similar. Four chromosomal gains and losses and two specific genes showed prognostic value and may be involved in tumour progression.

Key words: ITAC, sinonasal adenocarcinoma, microarray CGH, MLPA, DNA ploidy

\section{Introduction}

ITAC represents approximately $25 \%$ of all malignant sinonasal tumours. It arises almost exclusively in the ethmoid sinus and is strongly related to occupational wood and leather dust exposure ${ }^{(1-5)}$. The median age of onset lies between 50 and 60 years ${ }^{(1,2,6)}$. Four main histopathological subtypes are distinguished: papillary, colonic, solid and mucinous (alveolar goblet and signet ring) type, while a proportion of cases display more than one subtype ${ }^{(7)}$. ITAC tumours have a low tendency to develop lymphatic or distant metastases, however, local recurrences are very frequent and constitute the main cause of death ${ }^{(8-10)}$. The combined use of both surgery and radiotherapy is reported in the literature as the gold standard treatment ${ }^{(1-2)}$. ITAC patients carry a poor prognosis, with a 5 -year survival between $40 \%$ and
$60 \%{ }^{(6-13)}$. Both disease stage and histopathological subtype are of prognostic value ${ }^{(1,7,14)}$.

The low incidence and the apparent lack of early lesions precursor to ITAC makes its study difficult. Hence, little is known about the genetic changes involved in the development of ITAC. Most genetic studies on ITAC have focussed on specific genes involved in colorectal adenocarcinoma (CRC) because of their histological similarities. Comparing with CRC, these studies have indicated less frequent mutation in TP53 and activation of Wnt/ß-catenin, while K-ras or BRAF mutations and microsatellite instability (MSI) are almost absent ${ }^{(14-24)}$. A number of studies reported EGFR overexpression in 20-32\% of ITACs, and absence of mutations ${ }^{(25-27)}$. This demonstrates that ITAC is not genetically similar to CRC. Until the present moment, three genome-wide 
analyses using classical and microarray CGH have been published ${ }^{(28-30)}$. These studies showed that, with an exception for the papillary subtype, most ITACs carry complex karyotypes with hotspots of chromosomal gains at $5 p, 7 q, 8 q, 12 p$ and $20 q$, and losses at $4 q, 5 q, 8 p, 17 p$ and 18q. Either due to a low number of cases or to the absence of clinical and follow-up data, neither of these studies has come up with specific genetic events that are related to prognosis.

In this study, we have analysed 37 clinically well-described primary tumours by means of microarray CGH. For confirmation of the results, we performed MLPA (multiplex-ligation probe amplification), that included 65 cancer-related genes. In addition, we investigated the DNA ploidy status. Our aim was to obtain a high resolution map of recurrent genetic alterations and to correlate the genetic results with histopathological characteristics and clinical outcome.

\section{Materials and methods}

\section{Tissue samples}

All 37 cases analysed in this study arose in the ethmoid sinus region and were obtained from previously untreated male patients seen between 1998 and 2007. Informed consent was obtained from all patients. Tumour material was obtained through the Biobank Service and the study was approved by the ethical committee of our institute. All patients underwent radical surgery and in all cases resection margins were free of tumour. Thirty-four patients have had occupational exposure to wood dust with a mean of 33 years (range: 5-60 years), and 18 were tobacco and alcohol users. The mean age was 65 years (range 45-92 years). Nine tumours were stage I, seven stage II, ten stage III, and 11 stage IV. No patient had metastases at the time of diagnosis. Our series comprised of 4 papillary, 15 colonic, 5 solid and 13 mucinous type ITACs. Follow-up information was available with a average of 63 months (range 1-259). The 5 year survival rate was $41 \%$. All clinical data are given in Table 1 .

\section{Flow cytometry}

DNA ploidy was measured by flow cytometry as earlier described ${ }^{\left({ }^{30}\right)}$. In short, fresh tissue was disaggregated mechanically, suspended in citrate-phosphate-buffered solution, and stained with propidium iodide. Specimens were measured with the Cytoron flow cytometer (Ortho Diagnostic Systems), and results analysed according to the guidelines for implementation of clinical DNA cytometry.

\section{Microarray CGH}

Tumour DNA as well as normal reference DNA from blood of female donors was extracted using a Qiagen extraction kit (Qiagen $\mathrm{GmbH}$, Hilden, Germany). Microarray-CGH was carried out as described previously ${ }^{(31)}$. Briefly, sample DNA and reference
Table 1. Clinical and follow-up data of 37 ITAC patients.

\begin{tabular}{|c|c|}
\hline Feature & Number (\%) \\
\hline \multicolumn{2}{|l|}{ Localisation } \\
\hline Etmoid sinus & 37 (100\%) \\
\hline \multicolumn{2}{|l|}{ Gender } \\
\hline Male & 37 (100\%) \\
\hline \multicolumn{2}{|l|}{ Disease stage } \\
\hline I & $9(24 \%)$ \\
\hline II & 7 (19\%) \\
\hline III & $10(27 \%)$ \\
\hline IV & $11(30 \%)$ \\
\hline \multicolumn{2}{|l|}{ Histopathological type } \\
\hline Papillary & $4(11 \%)$ \\
\hline Colonic & $15(41 \%)$ \\
\hline Solid & $5(13 \%)$ \\
\hline Mucinous & $13(35 \%)$ \\
\hline \multicolumn{2}{|l|}{ Wood exposure } \\
\hline No & $3(8 \%)$ \\
\hline Yes & $34(92 \%)$ \\
\hline \multicolumn{2}{|l|}{ Smoker } \\
\hline No & 19 (51\%) \\
\hline Yes & $18(49 \%)$ \\
\hline \multicolumn{2}{|l|}{ Radiotherapy } \\
\hline No & $12(32 \%)$ \\
\hline Yes & $25(68 \%)$ \\
\hline \multicolumn{2}{|l|}{ Intracranial invasion } \\
\hline No & 27 (73\%) \\
\hline Yes & $10(27 \%)$ \\
\hline \multicolumn{2}{|l|}{ Distant metastasis } \\
\hline No & $31(84 \%)$ \\
\hline Yes & $6(16 \%)$ \\
\hline \multicolumn{2}{|l|}{ Local recurrence } \\
\hline No & $17(46 \%)$ \\
\hline Yes & $20(54 \%)$ \\
\hline \multicolumn{2}{|l|}{ Patient status } \\
\hline Alive & $15(41 \%)$ \\
\hline Died of disease & $19(51 \%)$ \\
\hline Died of other causes & $3(8 \%)$ \\
\hline
\end{tabular}

DNA (pooled from 10 different healthy female donors) were differently labelled by random priming. Three hundred ng test and three hundred ng reference DNA were hybridized to a 30,000 oligonucleotide array printed on Codelink activated slides (Amersham Biosciences, Barcelona, Spain). This array contained 29,134 oligos covering 28,830 unique genes. Hybridization and washing took place for two nights in a specialized hybridization chamber (GeneTAC/HybArray12 hybstation (Genomic Solutions/ 
Perkin Elmer). Images were acquired using a Microarray Scanner G2505B (Agilent Technologies). Analysis and data extraction were quantified by BlueFuse (BlueGnome, Cambridge, UK). The pooled female reference DNA served as an internal control of quality; since all tumours came from male patients, the chromosome $X$ clones normally showed loss whereas the chromosome $Y$ clones always showed gains. Normalization of the calculated ratios was done against the mode of all ratios. Graphics were plotted using a moving average of log2 ratios of 5 neighbouring clones. Gains and losses were defined as at least two neighbouring clones with deviations of 0.2 or more from log 2 ratio $=0.0$. High level amplification was considered when at least two neighbouring clones reached a log2 ratio of 1.0 or higher.

\section{MLPA}

MLPA was performed as described in detail previously ${ }^{(32)}$. Three kits were used, together analysing 65 cancer related genes distributed throughout the genome (SALSA P084, SALSA P005 and SALSA P105, MRC-Holland, Amsterdam, the Netherlands). Each probe is composed of two parts that hybridize to adjacent target sequences in the DNA. After a ligation step and a PCR amplification, each probe gives rise to a product with a unique size between 130 and 480 bp. Briefly, 100 ng DNA was denatured at $98^{\circ} \mathrm{C}$ for $5 \mathrm{~min}$ and hybridized with the MLPA probe mixture at $60^{\circ} \mathrm{C}$ for 16 hours. Ligation of the two parts of each probe was preformed by a thermostable ligase. All probe ligation products have the same end sequences and were amplified by PCR using the same primer pair for $60^{\circ} \mathrm{C} 1 \mathrm{~min}, 33$ cycles of $95^{\circ} \mathrm{C} 30 \mathrm{sec}$, $60^{\circ} \mathrm{C} 30 \mathrm{sec}$ and $72^{\circ} \mathrm{C} 1 \mathrm{~min}$, followed by $20 \mathrm{~min}$ at $72^{\circ} \mathrm{C}$ and kept cold at $4{ }^{\circ} \mathrm{C}$. The products were subsequently analysed on an $\mathrm{ABI}$ Prism 3100 sequencer and by GeneScan v3.7 software (Applied Biosystems, Warrington, UK).

Fourteen control experiments using normal DNA from 7 different donors were used to calculate median reference values and the standard deviations for every probe. Each tumour sample was analysed at least twice. For every gene, the relative copy number was calculated by dividing the average relative peak area of the tumour by the median relative peak area of the normal reference samples. When tumour/control ratio was higher than 1.2 and the standard deviation was $>1$ was interpreted as gain. If the ratio was lower than 0.8 and the standard deviation was $<1$ was interpreted as loss. It was interpreted as amplification when tumour/control ratio was higher than 2 and the standard deviation was also higher than 2.

\section{Statistical analysis}

The statistic analysis was carried out using Student's test, Pearson and Fisher Chi-square test. Survival estimation was analysed by Kaplan-Meier statistics with the log rank test. P-values $<0.05$ were considered significant. Copy number losses and gains were tested for univariant correlation with clinico-pathological and
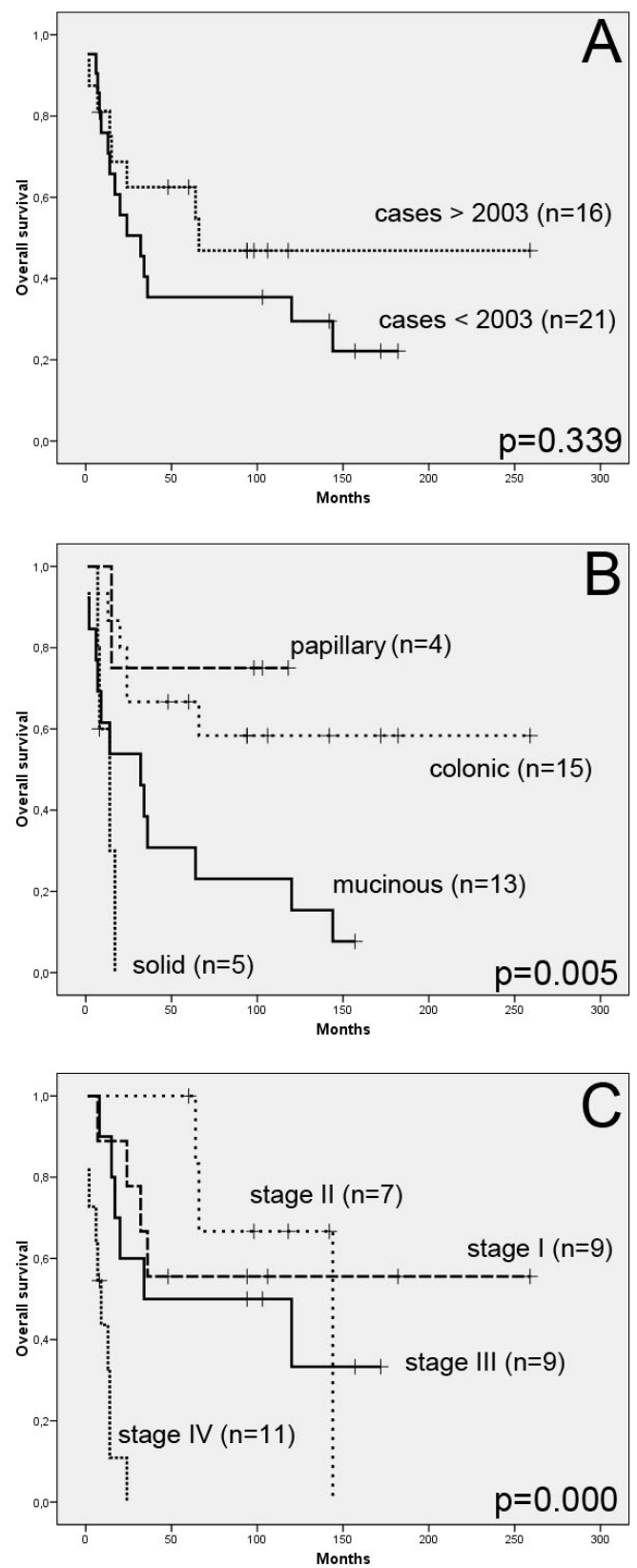

Figure 1. Kaplan-Meier survival analysis. (A) Overall survival of 37 patients according to years of treatment. (B) Overall survival of 37 patients according to histological subtype. (C) Overall survival of 37 patients according to disease stage.

cytometric characteristics (disease stage, histological type, local recurrence, intracranial invasion, metastasis, overall survival, and DNA ploidy).

\section{Results}

Follow-up

Twenty-five patients received radiotherapy after surgery. During the time of follow-up, 6 patients developed metastasis and 20 had local recurrence. The 5 year overall survival of all patients 

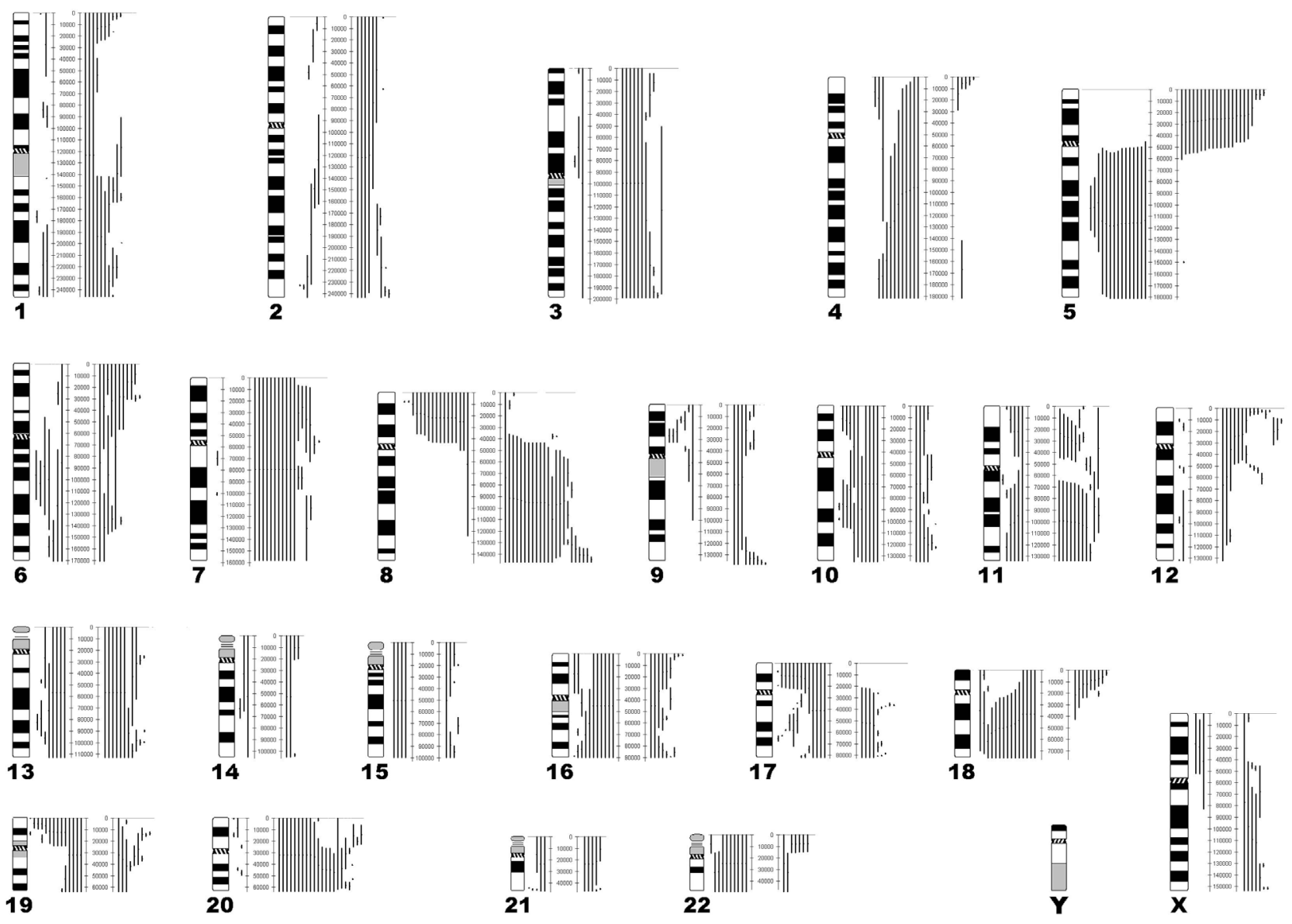

Figure 2. Overview of all copy number changes as detected by microarray comparative genomic hybridization (CGH). To the right of the pictogram of each chromosome, a scale is placed expressing the number of megabase pairs $(\mathrm{Mpb})$ counting from pter to qter. Copy number losses are presented as bars left to the Mbp-scale and copy number gains to the right.

was $41 \%$, however, a comparison of 21 patients treated in the years 1998-2003 with 17 patients in the years 2004-2008 revealed an improvement of the 5 -year overall survival from $35 \%$ to $63 \%$ (Figure 1). In addition, papillary and colonic type ITAC as well as tumour stages I - III showed a significantly better clinical outcome (Figure 1). At the time of writing, 15 patients were alive, 19 died of disease and 3 died of other causes.

\section{Genetic results}

DNA ploidy measurement was succesful in 34 tumours. Twentytwo (65\%) tumours were aneuploid, ranging from 1.1 to 2.3 , and 12 cases (35\%) were diploid.

Microarray CGH analysis revealed DNA copy number alterations in all cases. An overview of all gains and losses observed in the 37 cases is given in Figure 2. The major recurrent gains were detected at chromosome bands 5p15 (22 cases, 60\%), 8q24 (21 cases, 57\%), 20q13 (20 cases, 54\%), 20q11, and 8q21 (19 cases, 51\%), 20p13, and 7p11 (16 cases, 43\%), 12p13 (13 cases, 35\%), and 3q29 (11 cases, 30\%). Frequent losses were detected at 5q11-qter, 8p12-pter, and 18q12-23 (15 cases, 40\%), and 17p13, and 19p13 (13 cases, 35\%). High level amplification was found at $7 \mathrm{p} 12$ and $8 \mathrm{p} 11$ ( 3 cases), and at 8q24, 11p13 and 19p11 ( 2 cases). The exact size and genomic position of these regions are presented in Table 2 . DNA diploid cases showed significantly fewer copy number changes than DNA aneuploid cases (6.6 versus 15.1, Student's t-test, $p=0.0001$ ).

MLPA identified copy number alterations in one or more of the 65 analysed genes in all 37 tumours. Recurrent gains were observed for PTP4A3 (24 cases, 65\%), RECQL4 (22 cases, 60\%) both at 8q24, PTPN1 at 20q13 (17 cases, 46\%), EGFR at 7p12 (17 cases, $46 \%)$, and BCL2L1 at 20q11 (15 cases, 41\%), and frequent losses of CRK at 17p13 (16 cases, 43\%), CTSB at 8p22 (16 cases, 43\%) and TIMP2 at 17q25 (15 cases, 41\%). Figure 3 gives an overview of all MLPA findings. A total of fourteen gene amplifications were detected, of which EGFR at 7p11 and MYC and RECQL4 at $8 q 24$ occurred in two or more cases.

\section{Clinico-pathological correlations}

Diploid tumours had more favourable clinico-pathological features, including lower stage (50\% versus $32 \%$ stage I+II), less 


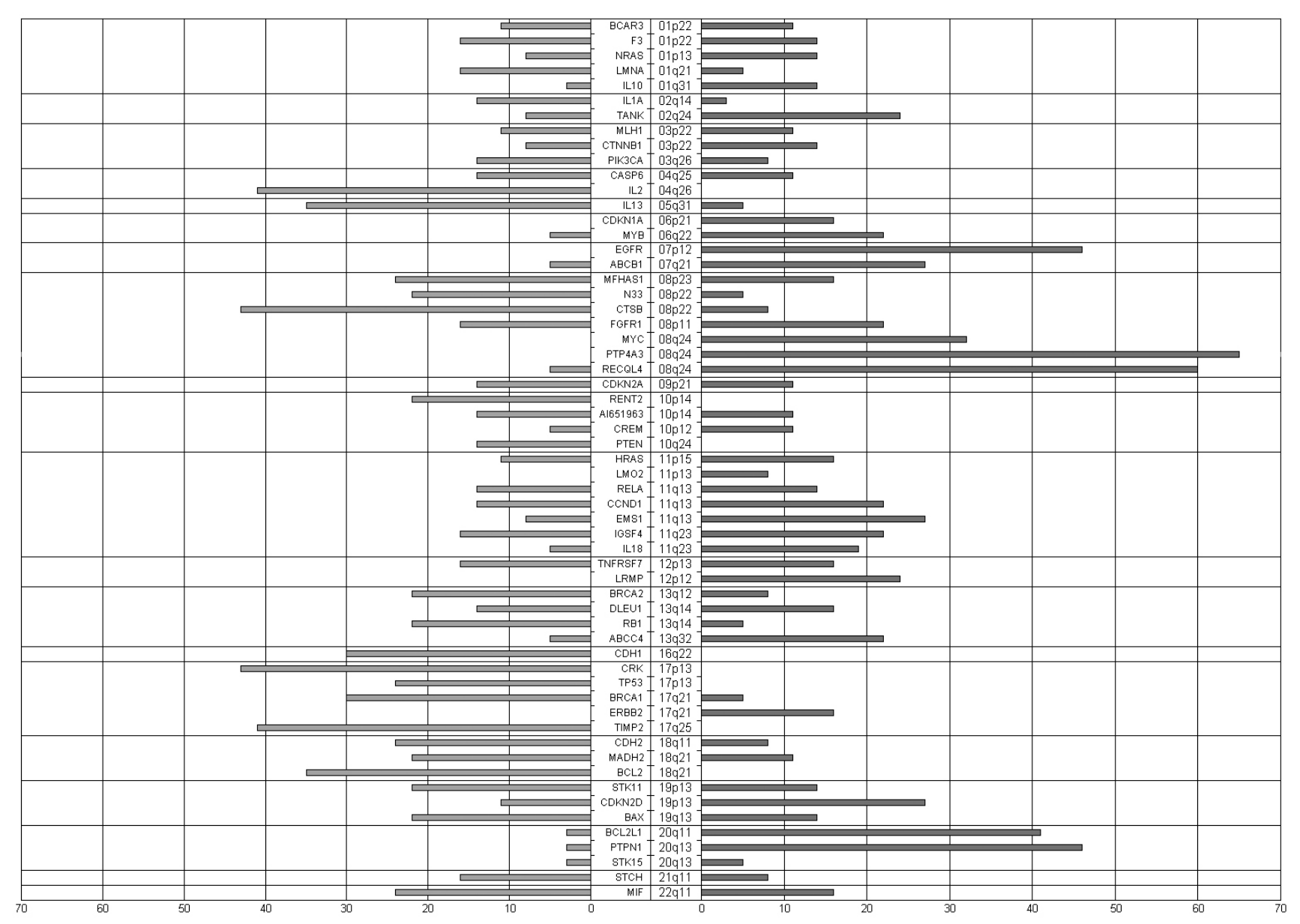

Figure 3. Genetic alterations in 37 primary ITACs detected by MLPA. All the probes analysed are presented according to their chromosomal location. Rows to the right represent $\%$ of gains and rows to the left represent $\%$ of losses.

intracranial invasion ( $10 \%$ versus $41 \%$ ) and better prognosis ( $50 \%$ versus $68 \%$ died of disease), although this did not reach significance. Of the four papillary type tumours, $75 \%$ were diploid and carried on average 5.5 copy number alterations, in contrast to the combined colonic, solid and mucinous type tumours, that showed only $25 \%$ of cases diploid and an average of 12.0 copy number alterations.

Thirty-four chromosomal regions by microarray CGH and 65 genes by MLPA frequently showing gain or loss were statistically analysed for correlation with clinical outcome. A significantly worse overall survival was observed for cases carrying microarray CGH losses at $4 q 32$-ter and gains at $1 q 22,6 p 22$ and 3q29, or carrying MLPA losses of TIMP2 at 17q21 and CRK at 17p13 (Figure 4). Cases with one or more of these aberrations also carried worse clinico-pathological characteristics.

\section{Discussion}

We have presented a genome-wide and detailed map of recurrent DNA copy number abnormalities in ITAC using microarray $\mathrm{CGH}$, and this map was confirmed by MLPA analysis of 65 genes.
As in most solid tumours, a proportion of cases was diploid, displayed relatively few copy number alterations and in general followed a less aggressive clinical course. Approximately two thirds of cases were aneuploid, carried a multitude of gains and losses and had worse clinical outcome. It remains to be clarified if these tumours represent another class of ITAC with a distinct genetic pathway of tumourigenesis. Among the few copy number aberrations in this subset of ITAC, the most frequent were gains of $5 p 15,7 p 11$ and $20 q 13$. These genetic changes may be regarded as early events.

Genetic studies on other tumours from the head and neck area such as squamous cell carcinoma (HNSCC) have reported frequent gains at 3q, 5p, 7p, 7q, 8q, 11q13, and 20q, and losses at $3 p, 5 q, 8 p, 9 p, 11 q$ ter, and $18 q^{(33)}$. Our data on ITAC show notable differences with HNSCC, including losses at $3 p$ and gains at $3 q, 4 q$ and $11 q 13$. These regions are hardly affected in ITAC. ITAC had more chromosomal changes in common with CRC, although gains at $5 p$, frequent in ITAC, are almost absent in $C R C^{(34)}$.

Although many copy number alterations concerned large stret- 
Table 2. Recurrent DNA copy number alterations by microarray CGH and MLPA.
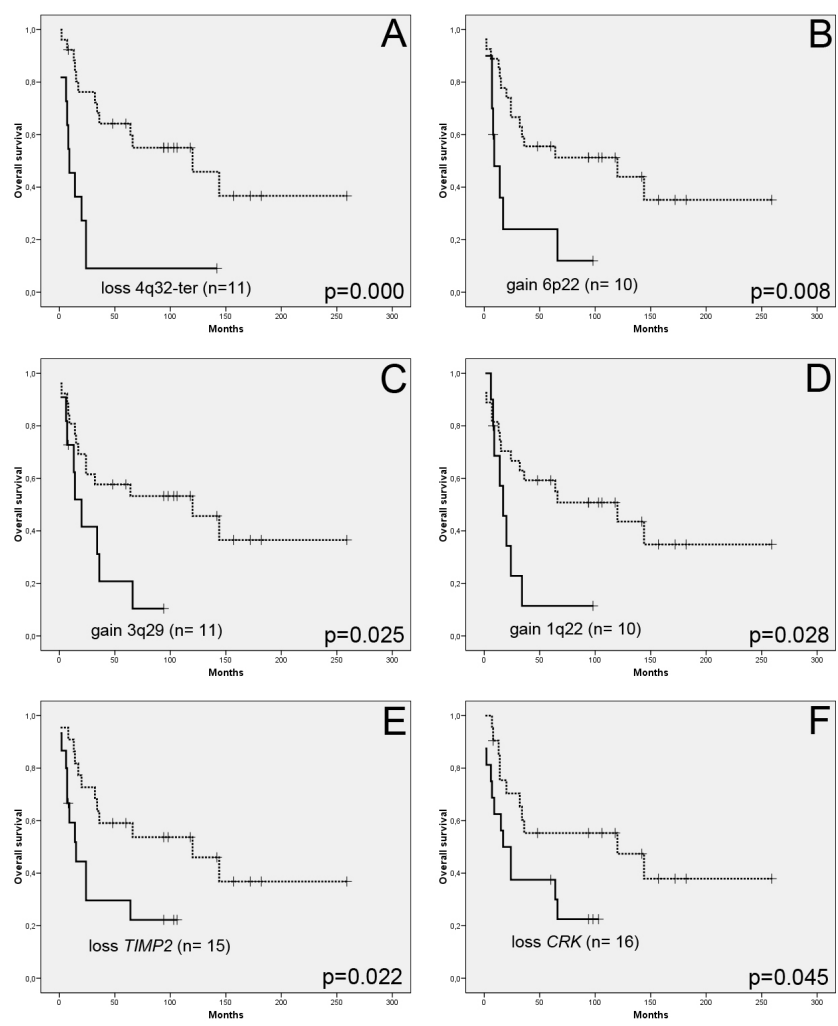

Figure 4. Kaplan-Meier survival analysis. (A) Overall survival of 37 patients according to the presence of $4 q 32$-ter copy number loss. (B) Overall survival of 37 patients according to the presence of 6 p22 copy number gain. (C) Overall survival of 37 patients according to the presence of 3 q29 copy number gain. (D) Overall survival of 37 patients according to the presence of $1 \mathrm{q} 22$ copy number gain. (E) Overall survival of 37 patients according to the presence of TIMP2 copy number loss. (F) Overall survival of 37 patients according to the presence of CRK copy number loss.

ches of chromosomes, the high resolution of the data allowed to narrow down common regions of overlap of a number of gains and losses and thus point to a limited number of candidate genes that may play a role in ITAC tumourigenesis.

At 7p12, the location of EGFR, gains were found in 16 cases, including 3 high level amplifications. EGFR is a member of the erbB family of tyrosine kinase receptor proteins, and regulates proliferation, angiogenesis, apoptosis, metastatic dissemination, and responsiveness to chemotherapy. Overexpression of EGFR in ITAC has been reported in approximately $20-32 \%$ of cases ${ }^{(25-}$ 27). Mutations in EGFR have not been reported for ITAC ${ }^{(25,35)}$. EGFR plays an important role in the pathogenesis of both HNSCC and CRC, where it is expressed in up to $80 \%$ of tumours and it has been associated with poor survival and risk of relapse ${ }^{(36,37)}$. In

\begin{tabular}{|c|c|c|c|c|}
\hline $\begin{array}{l}\text { Chromo- } \\
\text { some }\end{array}$ & $\begin{array}{l}\text { maCGH } \\
\text { Gains (\%) }\end{array}$ & $\begin{array}{c}\text { From-To } \\
\text { (Mbp) }\end{array}$ & Gene(s)* & $\begin{array}{c}\text { MLPA } \\
\text { Gains (\%) }\end{array}$ \\
\hline $5 p 15$ & $22(60 \%)$ & $1-5.3$ & $x$ & \\
\hline $8 q 24.3$ & $21(57 \%)$ & $142.1-143.2$ & РТР4A3 & $24(65 \%)$ \\
\hline $20 q 13$ & 20 (54\%) & $55.2-61.0$ & PTPN1 & 17 (46\%) \\
\hline $20 q 11$ & $19(51 \%)$ & $26.1-30.9$ & BCL2L1 & $15(41 \%)$ \\
\hline $8 q 21$ & $19(51 \%)$ & $77.4-80.9$ & $x$ & \\
\hline $20 \mathrm{p} 13$ & $16(43 \%)$ & $1-2.5$ & $x$ & \\
\hline 7p11 & $16(43 \%)$ & $54.4-55.8$ & EGFR & 17 (46\%) \\
\hline $12 \mathrm{p} 13.3$ & $13(35 \%)$ & $1.8-3.2$ & LRMP & $9(24 \%)$ \\
\hline $3 q 28$ & $11(30 \%)$ & 194.7-198.9 & $x$ & \\
\hline $1 p 36$ & $10(27 \%)$ & $1-3.5$ & $x$ & \\
\hline $1 q 22-23$ & $10(27 \%)$ & $156.4-162.7$ & $x$ & \\
\hline $6 p 22$ & $10(27 \%)$ & $27.2-29.9$ & $x$ & \\
\hline $11 q 13$ & $10(27 \%)$ & $68.2-71.4$ & $\begin{array}{l}\text { EMS1, } \\
\text { CCND1 }\end{array}$ & $\begin{array}{c}8-10(22- \\
27 \%)\end{array}$ \\
\hline $11 q 14-22$ & $10(27 \%)$ & 79.4-109.6 & $x$ & \\
\hline $12 \mathrm{p} 13.2$ & $10(27 \%)$ & $9.2-12.7$ & TNFRSF7 & $6(16 \%)$ \\
\hline $13 q 33$ & $10(27 \%)$ & $101.2-102.0$ & $x$ & \\
\hline $1 q 42$ & $9(24 \%)$ & $210.2-229.9$ & $x$ & \\
\hline $9 q 34$ & $9(24 \%)$ & $136.7-138.2$ & $x$ & \\
\hline $13 q 31$ & $9(24 \%)$ & $88.9-90.6$ & $x$ & \\
\hline $18 p$ & $9(24 \%)$ & $1-4.4$ & $x$ & \\
\hline $11 \mathrm{p} 14-15$ & $8(22 \%)$ & $22.7-30.8$ & HRAS & $6(16 \%)$ \\
\hline \multirow[t]{2}{*}{$\mathrm{Xq28}$} & $8(22 \%)$ & $150.6-152.1$ & $x$ & \\
\hline & $\begin{array}{c}\text { Amplifica- } \\
\text { tions }\end{array}$ & & & $\begin{array}{l}\text { Amplifica- } \\
\text { tions }\end{array}$ \\
\hline $6 q 23$ & 2 & $132.5-138.7$ & CMYB & 0 \\
\hline $7 p 12$ & 3 & $54.4-55.8$ & EGFR & 3 \\
\hline $8 p 11$ & 3 & $37.6-38.7$ & FGFR1 & 0 \\
\hline $8 q 24$ & 2 & 128.3-129.1 & cMYC & 3 \\
\hline $11 p 13$ & 2 & $24.7-27.6$ & $x$ & \\
\hline $11 \mathrm{p} 13$ & 2 & $44.9-46.9$ & $x$ & \\
\hline \multirow[t]{2}{*}{$19 p 13$} & 2 & $13.2-14.1$ & $x$ & \\
\hline & Losses (\%) & & & Losses (\%) \\
\hline 5q11-qter & $15(40 \%)$ & 83.4-121.8 & $x$ & \\
\hline 8p12-pter & $15(40 \%)$ & $7.2-8.2$ & $\begin{array}{c}\text { MHAS, } \\
\text { CTSB, N33 }\end{array}$ & $\begin{array}{c}8-16(22- \\
43 \%\end{array}$ \\
\hline $18 q 12-23$ & $15(40 \%)$ & 46.9-76.1 & $\mathrm{BCL} 2$ & $13(35 \%)$ \\
\hline $17 p 13$ & $13(35 \%)$ & $6.6-7.7$ & TP53, CRK & $\begin{array}{c}9-16(24- \\
43 \%)\end{array}$ \\
\hline $19 \mathrm{p} 13$ & $13(35 \%)$ & $1-8.9$ & $x$ & \\
\hline 4qter & $11(30 \%)$ & 158.0-191.7 & $x$ & \\
\hline $10 q 21$ & $11(30 \%)$ & $68.2-70.3$ & $x$ & \\
\hline $10 q 22-23$ & $11(30 \%)$ & $84.3-89.9$ & PTEN & $5(14 \%)$ \\
\hline $16 q 24$ & $11(30 \%)$ & $88.6-88.9$ & $x$ & \\
\hline $22 q$ & $9(24 \%)$ & $15.5-49.3$ & MIF & \\
\hline $17 q 21$ & $8(22 \%)$ & $39.2-39.9$ & ERBB2 & $0(0 \%)$ \\
\hline $17 q 25$ & $6(16 \%)$ & $80.1-81.7$ & TIMP2 & $15(41 \%)$ \\
\hline
\end{tabular}


our series, EGFR copy number gains did not correlate with any of the clinico-pathological parameters and does not seem to be of prognostic value, confirming previous findings in ITAC ${ }^{(25-27)}$. Nonetheless, EGFR can be of relevance for a possible treatment of ITAC with specific inhibitors, analogous to other tumours as lung cancer, colorectal cancer or head and neck cancer. Amplifications at 8q24 at the location of cMYC were detected in two cases, however, 21 cases with gains indicated a a $1 \mathrm{Mbp}$ common region of overlap at 8q24.3, harbouring PTP4A3 but not cancer-related genes as CMYC or FAK. The protein encoded by PTP4A3 belongs to a class of protein tyrosine phosphatases, which stimulates progression from $\mathrm{G} 1$ into $S$ phase during mitosis. Interestingly, PTP4A3 overexpression in CRC has been related to the development of distant metastasis (38). Gains of PTP4A3 were also detected in this study by MLPA, and was observed more frequently in tumours with metastasis (Fisher exact, $\mathrm{p}=0.058$ ), with more advanced stages (Fisher exact, $\mathrm{p}=0.033$ ), and with intracranial invasion (Fisher exact, $\mathrm{p}=0.054$ ).

Chromosome 20q showed two regions with recurring gains, 20q11 and 20q13.3. PTPN1 at 20q13 and BCL2L1 at 20q11 in the MLPA analysis concurred with the microarray CGH data. Both these regions have also been implicated in CRC and have been associated with liver metastases and poor outcome ${ }^{(39,40)}$. PTPN 1 (or PTP1B) is a non-receptor protein-tyrosine phosphatase involved in many cellular signaling pathways, including EGFR and ERK. It may function as a suppressor but also as a promotor of neoplastic transformation. Gene amplification and protein overexpression in up to $72 \%$ of cases have been reported in breast cancer, especially in Her2/neu-positive tumours ${ }^{(41)}$. In our series of ITACs, gains of PTPN1 were found more frequently in tumours with intracranial invasion and with worse overall survival, although not statistically significant (Fisher exact $\mathrm{p}=0.078$ and $\mathrm{p}=0.093$, respectively).

Other high level amplifications were found at $8 \mathrm{p} 11$ ( 3 cases), $11 \mathrm{p} 13,19 \mathrm{p} 13$ and $6 \mathrm{q} 23$ (2 cases). A cancer-related gene at 8p11 may be FGFR1. Apart from the two cases with amplification, MLPA identified 6 other cases with FGFR1 copy number gain. One previous study using FISH on sinonasal tumours revealed FGFR1 amplifications, but only in squamous carcinomas and not in ITAC ${ }^{(42)}$. The two amplifications at $6 q 23$ included the site of the oncogene CMYB. MLPA did not confirm these amplifications, but did indicate 8 cases with copy number gain, suggesting it may play a role in ITAC. Activation of CMYB can also be caused by chromosomal translocation, as has been shown in adnoid cystic carcinoma ${ }^{(43,44)}$, however, we are not aware of reports on CMYB translocations in ITAC. Finally, the amplications at $11 \mathrm{p} 13$ and 19p13 were not confirmed by MLPA, as none of the probes localized to these regions.

The 5 -year overall survival of $41 \%$ in our series is low compared to other recently published series that reported $40-60 \%$ survival or better ${ }^{(6-13)}$, although we observed a trend toward a better survival rate over the years (Figure 1). We believe the patients included in this study do reflect correctly the clinical characteristics known of ITAC, for example the prognostic value of histological subtype and disease stage (Figure 1). Therefore we were confident that our series allowed for univariant survival analysis according to the detected genetic alterations; multivariant analysis was not feasible because of the relatively low number of cases.

Chromosomal loss at 4q32-ter was notably correlated with worse clinical outcome $(p=0.000)$, as did gains at $1 q 22,3 q 29$ and $6 \mathrm{p} 22$ to a lesser extent (Figure 4). Unfortunately, none of the 65 genes in the MLPA analysis localized in these regions, and we cannot speculate on specific genes that may be the drivers. Loss of 4q32-ter not only correlated with poor overall survival, but also with established clinical prognostic factors, as tumour stage, intracranial invasion and the development of recurrences. Among the MLPA results, loss of TIMP-2 (17q25) correlated with several poor overall survival, advanced tumour stage and intracranial invasion, and was observed more frequently in the mucinous type. TIMP-2 is a tissue inhibitor of metalloproteinases and has been related to poor prognosis in other studies ${ }^{(45-47)}$, however, more investigation is needed to clarify a possible role in ITAC.

\section{Conclusion}

ITACs generally show complex karyotypes as do most solid tumours. Papillary, colonic, solid and mucinous subtypes of ITAC did not appear genetically different from each other. Diploid tumours harboured a significantly lower number of chromosomal abnormalities and had more favourable clinical features. The most frequent gains were found at 5p13, 7p12 (EGFR), 8q24 (cMYC and PTP4A3) and 20q13 (PTPN1) and losses at large regions of chromosome arms $5 q, 8 p$ and 18q. Four chromosomal gains and losses and two specific genes showed prognostic value and may be involved in tumour progression.

\section{Acknowledgements}

This work was supported by grants PI05-1387, PI08-1599, PI11929, PI13-646 and EMER07-048 of Fondos de Investigación Sanitaria (FIS) and RD12/0020/0034 of Red Temática de Investigación Cooperativa en Cáncer (RTICC), Spain. The authors thank Eva Allonca for her technical support, and Bauke Ylstra of the Microarray Facility of the VU University Medical Center, Amsterdam, The Netherlands.

\section{Authorship contribution}

JPE: maCGH and MLPA, statistics, overall data interpretation, writing manuscript. ALH: maCGH, critical lecture manuscript. MC: Clinical data collection, critical lecture manuscript. FL: Patient and clinical data collection, critical lecture manuscript. SPA: Tissue sample processing, DNA extraction. BV: Histopathological 
evaluation, critical lecture manuscript. JLL: Study design, Patient collection, critical lecture manuscript. MAH: Study design, statistics, overall data interpretation, writing manuscript.
Conflict of interest

All the authors certify that they have no conflict of interest or financial relationship with any entity mentioned in the paper.

\section{References}

1. Llorente JL, López F, Suárez C, Hermsen M. Sinonasal carcinoma: Clinical, pathological and genetic advances for new therapeutic opportunities. Nat Rev Clin Oncol. 2014 11: 460-72.

2. Lund VJ, Stammberger $H$, Nicolai $P$, et al. on behalf of the European Rhinologic Society Advisory Board on Endoscopic Techniques in the Management of Nose, Paranasal Sinus and Skull Base Tumours. European position paper on endoscopic management of tumours of the nose, paranasal sinuses and skull base. Rhinol Suppl. 2010; (22):1-143.

3. Cantu G, Solero CL, Mariani L, et al. Intestinal type adenocarcinoma of the ethmoid sinus in wood and leather workers: a retrospective study of 153 cases. Head Neck 2011; 33: 535-542.

4. IARC Working Group on the Evaluation of Carcinogenic Risks to Humans. Arsenic, metals, fibres, and dusts. IARC Monogr Eval Carcinog Risks Hum. 2012; 100: 11-465.

5. Bimbi G, Saraceno MS, Riccio $S$, et al. Adenocarcinoma of Ethmoid Sinus: An Occupational Disease. Acta Otorhinolaryngol Ital. 2004; 24: 199-203.

6. Youlden DR et al. International comparisons of the incidence and mortality of sinonasal cancer. Cancer Epidemiol. 2013; 37: 770-779.

7. Franchi A, Santucci M, Wening B. Adenocarcinoma. In: Barnes L, Evenson JW, Reichard P, Sidransky D, eds. World Health Organization classification of tumours. Pathology and genetics of head and neck tumours. Lyon: IARC, 2005, 20-23.

8. Cantu G, Solero CL, Miceli R, et al. Anterior craniofacial resection for malignant paranasal tumors: a monoinstitutional experience of 366 cases. Head Neck 2012; 34: 78-87.

9. Bhayani MK, Yilmaz T, Sweeney A, et al. Sinonasal adenocarcinoma: a 16-year experience at a single institution. Head Neck. 2014; 36: 1490-1496.

10. Choussy O, Ferron C, Vedrine PO et al. Adenocarcinoma Of Ethmoid: A Gettec Retrospective Multicenter Study Of 418 Cases. Laryngoscope 2008; 118: 437-443.

11. Nicolai P, Schreiber A, Bolzoni Villaret A, et al. Intestinal type adenocarcinoma of the ethmoid: Outcomes of a treatment regimen based on endoscopic surgery with or without radiotherapy. Head Neck. 2015 Jun 3. doi: 10.1002/hed.24144.

12. Camp S, Van Gerven L, Poorten VV, et al. Long-term follow-up of 123 patients with adenocarcinoma of the sinonasal tract treated with endoscopic resection and postoperative radiation therapy. Head Neck. 2016 Feb;38(2):294-300.
13. Vergez S, du Mayne MD, Coste A, et al. Multicenter study to assess endoscopic resection of 159 sinonasal adenocarcinomas. Ann Surg Oncol. 2014; 21:1384-1390.

14. Díaz-Molina JP, Llorente JL, Vivanco B, et al. Wnt-pathway activation in intestinal-type sinonasal adenocarcinoma. Rhinology 2011; 49: 593-599.

15. Holmila R, Bornholdt J, Heikkila P et al Mutations In Tp53 Tumour Suppressor Gene In Wood Dust-Related Sinonasal Cancer. Int J Cancer 2010; 127: 578-88.

16. Pérez-Escuredo J, Martínez JG, Vivanco B, et al. Wood dust-related mutational profile of TP53 in intestinal-type sinonasal adenocarcinoma. Hum Pathol. 2012; 43: 1894-1901.

17. Perrone F, Oggionni M, Birindelli S, et al. Tp53, P14arf, P16ink4a And H-Ras Gene Molecular Analysis In Intestinal-Type Adenocarcinoma Of The Nasal Cavity And Paranasal Sinuses. Int J Cancer 2003; 105: 196-203.

18. Bossi P1, Perrone F, Miceli R, et al. TP53 status as guide for the management of ethmoid sinus intestinal-type adenocarcinoma. Oral Oncol. 2013; 49: 413-419.

19. Franchi A, Palomba A, Fondi C, et al. Immunohistochemical investigation of tumorigenic pathways in sinonasal intestinal-type adenocarcinoma. A tissue microarray analysis of 62 cases. Histopathology. 2011; 59: 98-105.

20. Perez-Ordonez B, Huynh N N, Berean KW, Jordan RCK. Expression of mismatch repair proteins, $\beta$-catenin, and E-cadherin in intestinal-type sinonasal adenocarcinoma. J Clin Pathol.2005; 57: 1080-1083.

21. Martínez JG, Pérez-Escuredo J, López F, et al. Microsatellite instability analysis of sinonasal carcinomas. Otolaryngol Head Neck Surg. 2009; 140: 55-60.

22. Bornholdt J, Hansen J, Steiniche T, et al. KRAS mutations in sinonasal cancers in relation to wood dust exposure. BMC Cancer 2008; 8: 53.

23. López F, García Inclán C, Pérez-Escuredo J, et al. KRAS and BRAF mutations in sinonasal cancer. Oral Oncol. 2012; 48: 692-697.

24. Frattini M1, Perrone F, Suardi S, et al. Phenotype-genotype correlation: challenge of intestinal-type adenocarcinoma of the nasal cavity and paranasal sinuses. Head Neck 2006; 28: 909-915.

25. García-Inclán C, López F, Pérez-Escuredo J, et al. EGFR status and KRAS/BRAF mutations in intestinal-type sinonasal adenocarcinomas. Cell Oncol. (Dordr.) 2012; 35: 443-450.

26. Franchi A, Fondi C, Paglierani $M$, et al. Epidermal growth factor receptor expression and gene copy number in sinonasal intestinal type adenocarcinoma. Oral Oncol. 2009; 45: 835-838.
27. Projetti F, Durand K, Chaunavel A, et al. Epidermal growth factor receptor expression and KRAS and BRAF mutations: study of 39 sinonasal intestinal-type adenocarcinomas. Hum Pathol. 2013; 44: 2116-2125.

28. Ariza M, Llorente $J$, Alvarez Marcos C, et al. Comparative genomic hybridization of primary sinonasal adenocarcinomas. Cancer 2004; 100: 335-341.

29. Korinth D, Pacyna-Gengelbach $M$, Deutschmann N, et al. Chromosomal imbalances in wood dust-related adenocarcinomas of the inner nose and their associations with pathological parameters. J Pathol. 2005; 207: 207-215.

30. Hermsen MA, Llorente JL, Pérez-Escuredo $J$, et al. Genome-wide analysis of genetic changes in intestinal-type sinonasal adenocarcinoma. Head Neck 2009; 31: 290-297.

31. López F, Llorente JL, García-Inclán C, et al. Genomic profiling of sinonasal squamous cell carcinoma. Head Neck. 2011; 33: $145-$ 153.

32. Costales M, López F, García-Inclán C, et al. Orthotopic murine model of squamous cell carcinoma of the sinonasal cavities. Head Neck 2015. 37, 12: 1769-1775.

33. Leemans CR, Braakhuis BJ, Brakenhoff RH. The molecular biology of head and neck cancer. Nat Rev Cancer 2011; 11: 9-22.

34. Nakao K, Mehta KR, Fridlyand J, et al. HighResolution Analysis Of Dna Copy Number Alterations In Colorectal Cancer By ArrayBased Comparative Genomic Hybridization. Carcinogenesis 2004; 25: 1345-1357.

35. Franchi $A$, Innocenti DR, Palomba $A$, et al. Low prevalence of K-RAS, EGFR and BRAF mutations in sinonasal adenocarcinomas. Implications for anti-EGFR treatments. Pathol Oncol Res. 2014; 20: 571-579.

36. Temam S, Kawaguchi H, El-Naggar AK et al., Epidermal growth factor receptor copy number alterations correlate with poor clinical outcome in patients with head and neck squamous cancer. J Clin Oncol. 2007; 25: 2164-2170.

37. Ljuslinder I, Melin B, Henriksson ML et al. Increased epidermal growth factor receptor expression at the invasive margin is a negative prognostic factor in colorectal cancer. Int J Cancer 2011; 128: 2031-2037.

38. Kato H, Semba S, Miskad UA, et al. High Expression Of Prl-3 Promotes Cancer Cell Motility And Liver Metastasis In Human Colorectal Cancer: A Predictive Molecular Marker Of Metachronous Liver And Lung Metastases. Clin Cancer Res 2004; 10: 73187328.

39. Yang SH, Seo MY, Jeong HJ, et al. Gene copy number change events at chromosome 20 and their association with recurrence in gastric cancer patients. Clin Cancer Res. 
2005; 11: 612-620.

40. Bruin SC, He Y, Mikolajewska-Hanclich I, et al. Molecular alterations associated with liver metastases development in colorectal cancer patients. Br J Cancer. 2011; 105: 281-287.

41. Bentires-Alj M, Neel BG. Protein-tyrosine phosphatase $1 \mathrm{~B}$ is required for HER2/Neuinduced breast cancer. Cancer Res. 2007; 67: 2420-2424.

42. Schröck A, Göke F, Wagner P, et al. Fibroblast growth factor receptor- 1 as a potential therapeutic target in sinonasal cancer. Head Neck. 2014;3 6: 1253-1257.

43. Persson M, Andrén Y, Mark J, et al. Clinically significant copy number alterations and complex rearrangements of MYB and NFIB in head and neck adenoid cystic carcinoma. Genes Chromosomes Cancer 2012; 51: 805-817.

44. Costa AF, Altemani A, García-Inclán C, et al.
Analysis of MYB oncogene in transformed adenoid cystic carcinomas reveals distinct pathways of tumor progression. Lab Invest. 2014; 94: 692-702.

45. Ross JS, Kaur P, Sheehan CE et al. Prognostic Significance Of Matrix Metalloproteinase 2 And Tissue Inhibitor Of Metalloproteinase 2 Expression In Prostate Cancer. Mod Pathol. 2003; 16: 198-205.

46. Kallakury BV, Karikehalli S, Haholu A et al. Increased Expression Of Matrix Metalloproteinases 2 And 9 And Tissue Inhibitors Of Metalloproteinases 1 And 2 Correlate With Poor Prognostic Variables In Renal Cell Carcinoma. Clin Cancer Res. 2001; 7:3113-3119.

47. Mendes $\mathrm{O}$, Kim HT, Lungu G, Stoica G. Mmp2 Role In Breast Cancer Brain Metastasis Development And Its Regulation By Timp2 And Erk1/2. Clin Exp Metastasis. 2007: 24: 341-351.

\author{
Mario A. Hermsen \\ Dept. Otolaryngology \\ Instituto Universitario de Oncología \\ del Principado de Asturias (IUOPA) \\ Hospital Universitario Central de \\ Asturias \\ Avenida de Roma $\mathrm{s} / \mathrm{n}$ \\ 33011 Oviedo \\ Spain
}

Tel: +34-985-107 937

Fax: +34-985-108 015

E-mail: mhermsen@hca.es

\section{ADVERTISEMENT}

\section{3rd International Course in Modern Rhinoplasty Techniques}

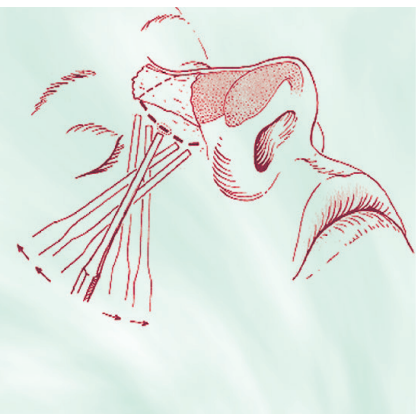

October 26, 27 and 28, 2016

Teacher of Honour:

Dr S Mark Taylor

Dalhousie University in Halifax, Nova Scotia, Canada

\section{Tuition fee}

complete course - Euro 1475 ,

(incl. dissection) FRESH FROZEN CADAVER

For further information contact:

Academic Medical Center of the University of Amsterdam,

Department of Otorhinolaryngology,

The Netherlands,

Email: m.b.vanhuiden@amc.uva.nl

Fax: 0031205669573

Website: www.rhinoplastycourse.nl

In affiliation with the European Academy of Facial Plastic Surgery The course is under the auspices of the ERS

\section{4th INTERNATIONAL COURSE IN ADVANCED SINUS SURGERY TECHNIQUES}

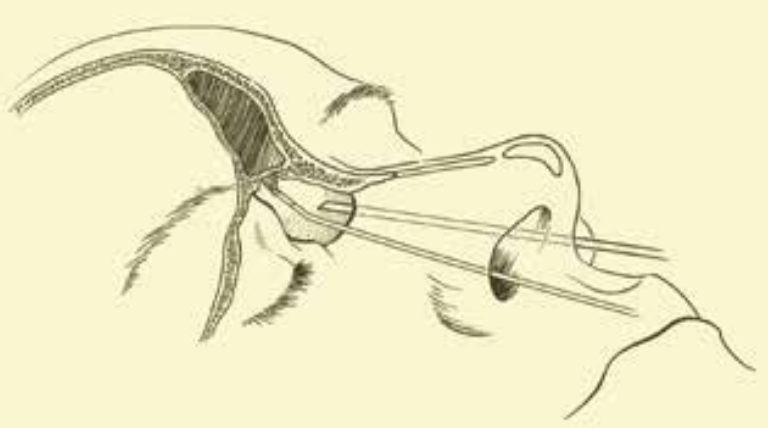

March 15-17, 2017

Department of Otorhinolaryngology

Academic Medical Center of the

University of Amsterdam The Netherlands

For further information contact Wytske J. Fokkens, $M D, P h D$

ENT dept. AMC Course Secretariat

Tel: 0031205668586 / Fax 0031205669573

Email:m.b.vanbuiden@amc.uva.nl

Web: monv.sinuscourse.nl 